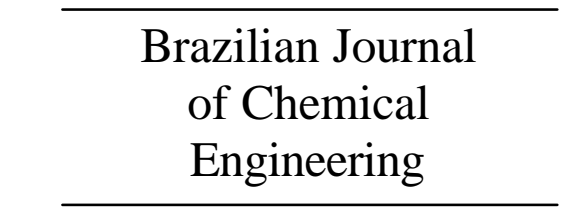

ISSN 0104-6632 Printed in Brazil

Vol. 21, No. 03, pp. 459 - 470, July - September 2004

\title{
SIMULATION OF EMULSION COPOLYMERIZATION REACTIONS IN A CONTINUOUS PULSED SIEVE-PLATE COLUMN REACTOR
}

\author{
C. Sayer and R. Giudici* \\ Departamento de Engenharia Química, Escola Politécnica, Universidade de São Paulo, \\ Caixa Postal 61548, CEP 05424-970, São Paulo - SP, Brazil. \\ Phone (11) 3818-2246, Fax (11) 3813-2380, \\ E-mail: csayer@1scp.pqi.ep.usp.br \\ E-mail: rgiudici@usp.br
}

(Received: February 20, 2003 ; Accepted: April 3, 2004)

\begin{abstract}
This work addressed the viability of using a pulsed sieve-plate column reactor to carry out continuous vinyl acetate/butyl acrylate emulsion copolymerization reactions. A rigorous mathematical model of emulsion copolymerization reactions in a tubular reactor with axial dispersion was used for this purpose. Operational conditions were defined to attain high monomer conversions at the reactor outlet in a relatively short residence time and, at the same time, produce a copolymer with a more homogeneous composition. Keywords: continuous pulsed sieve-plate column (PSPC), emuls ion copolymerization, modeling.
\end{abstract}

\section{INTRODUCTION}

In previous work (Palma et al., 2001a, 2001b; Sayer et al., 2002a, 2002b) a new type of reactor, the pulsed sieve-plate column (PSPC), had been studied for emulsion vinyl acetate homopolymerization reactions. It had been observed that transforming batch emulsion polymerization reactions into continuous reactions in a PSPC may be an attractive way to intensify this process since: 1) high conversions can be achieved in short residence times; 2) the process is safer in the PSPC than in a stirred tank batch or continuous reactor, due to the high heat exchange capacity of the PSPC and 3) due to the continuous operation, variations in product quality, which are commonly found from one batch to the next, are avoided.

In batch copolymerizations carried out with comonomers that have very different reactivity ratios, a copolymer composition drift is observed during the reaction (Araújo, 1997). This same behavior is also observed in continuous reactions in tubular reactors that are not perfectly mixed. Van den Boomen et al. (1999) and Scholtens et al. (2001) conducted experimental studies of styrene/methyl acrylate emulsion copolymerization reactions (reactivity ratios $\mathrm{r}_{\mathrm{Sty} / \mathrm{MA}}=0.73$ and $\mathrm{r}_{\mathrm{MA} / \mathrm{Sty}}=0.19$ ) in a continuous pulsed column reactor and verified that for this system, which does not show differences in order of magnitude between the reactivity ratios, the copolymer composition can be controlled using lateral monomer feed streams.

This work addresses the viability of using the PSPC for vinyl acetate/butyl acrylate emulsion copolymerization reactions. This system was chosen due to its importance in the paint and paper coatings industries and for having very different reactivity ratios $\left(\mathrm{r}_{\mathrm{VA} / \mathrm{BA}}=0.037\right.$ and $\left.\mathrm{r}_{\mathrm{BA} / \mathrm{VA}}=6.35\right)$. A rigorous

*To whom correspondence should be addressed 
dynamic mathematical model of emulsion copolymerization reactions was used in this study. The effect of various process variables - axial dispersion, manipulated through the amplitude of the pulses; initiator and emulsifier concentrations; and lateral monomer feed streams - on conversion and copolymer composition was verified.

\section{DESCRIPTION OF THE PSPC REACTOR}

The PSPC (Figure 1) is composed of five stainless steel sections, each one with a length of
$1000 \mathrm{~mm}$ and an internal diameter of $40.0 \mathrm{~mm}$. The plates are stainless steel disks, each with $393 \mathrm{~mm}$ holes in a triangular arrangement, resulting in a free area of $22.3 \%$ on each plate. Plate spacing is $50 \mathrm{~mm}$, resulting in a free volume of $95.7 \%$ of the reactor.

In order to prevent demulsification and the consequent plugging of the reactor, a pulsation is superposed on the nominal axial flow. The pulsator is located at the bottom of the column and the stroke length and pulsation frequency may be adjusted within the ranges of 5 to $25 \mathrm{~mm}$ and 0.2 and $3.5 \mathrm{~Hz}$, respectively. Reactants are fed in the bottom and at points throughout the PSPC.

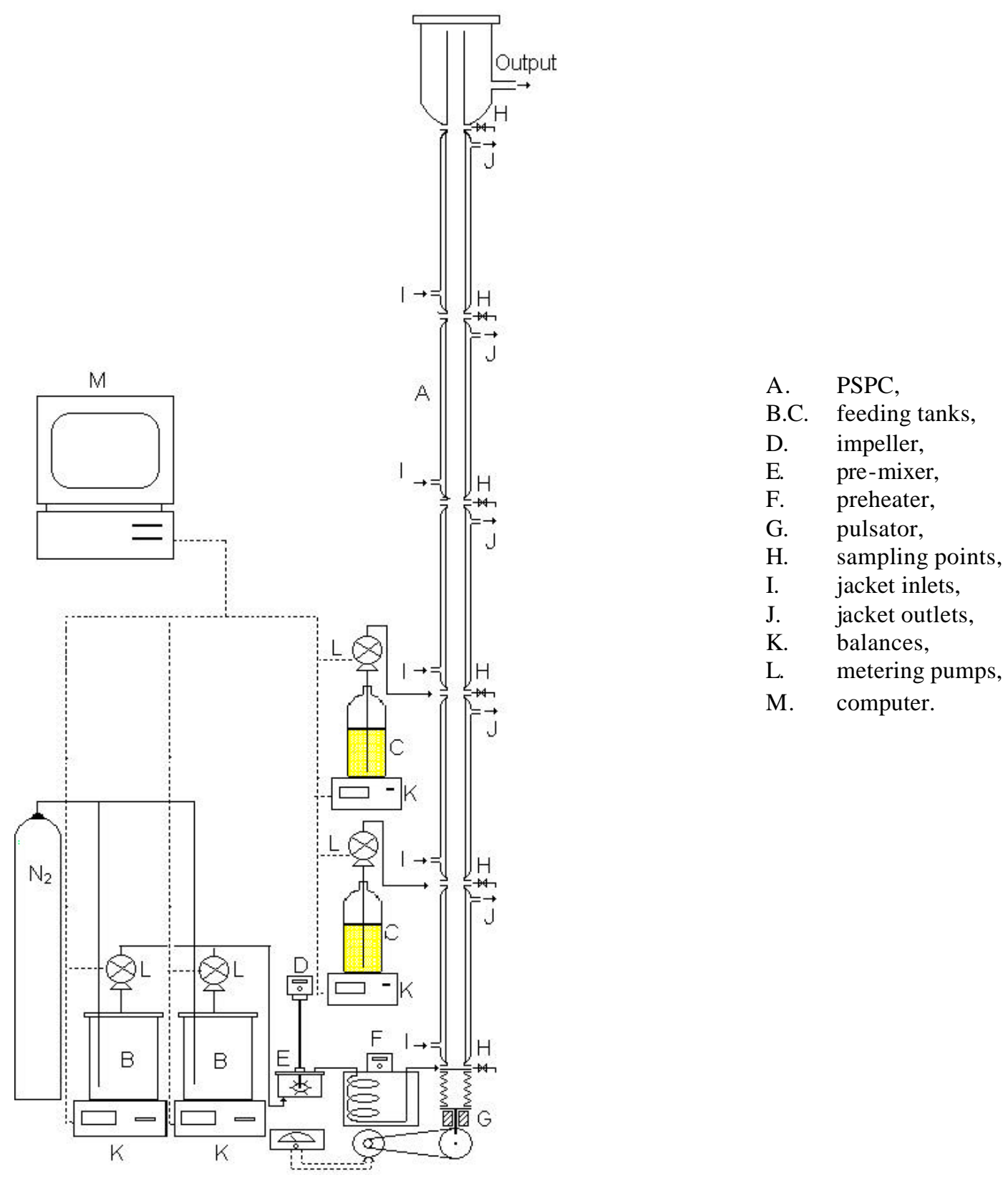

Figure 1: Diagram of the experimental setup: 


\section{MATHEMATICAL MODELING}

The mathematical model is based on a previous model of Sayer et al. (2002a) of emulsion homopolymerization reactions in the PSPC. In the elaboration/complementation of this model the following assumptions are made:

- Monomer concentrations in polymer particles, monomer droplets and aqueous phase are at thermodynamic equilibrium and are computed using the iterative procedure proposed by Omi et al. (1985).

- Total mass of polymer produced in the aqueous phase is negligible.

- Particle nucleation occurs through micelar and homogeneous mechanisms.

- Particle coagulation depends on initiator concentration.

- The average number of radicals per polymer particle is computed using the method proposed by Ugelstad et al. (1967).

- Polymer particles are spherical and monodisperse.

- The critical micelar concentration and the surface covered by one mol of emulsif ier are constant.

- The pseudo-steady-state assumption is valid for polymer radicals.

- Kinetic constants do not depend on chain length.

- Kinetic constants in the aqueous and polymer phases are the same.

- Radicals generated by initiation or chain transfer to monomer and polymer have similar reactivities.

- Reactions are conducted at constant temperature.

- Radial mixing is perfect.

- Average net forward velocity is constant.

- Axial mixing is represented by an effective axial dispersion coefficient.

- The boundary conditions of Danckwerts (1953) were applied to the axial dispersion model.

- The method of lines was used to solve the second-order partial differential equations.

The balance equations of continuous homopolymerization reactions in the PSPC were presented in Sayer et al. (2002a) and are shown in the Appendix. In the present work the following average coefficients were used to describe the copolymerization reactions:
Propagation:

$$
\mathrm{k}_{\mathrm{p}}[\mathrm{M}]_{\mathrm{p}}=\sum_{\mathrm{i}=\mathrm{A}, \mathrm{B}}\left(\mathrm{k}_{\mathrm{pAi}} \mathrm{P}_{\mathrm{Ap}}+\mathrm{k}_{\mathrm{pBi}} \mathrm{P}_{\mathrm{Bp}}\right)[\mathrm{i}]_{\mathrm{p}}
$$

Chain transfer to monomer:

$$
\mathrm{k}_{\mathrm{f}}[\mathrm{M}]_{\mathrm{p}}=\sum_{\mathrm{i}=\mathrm{A}, \mathrm{B}}\left(\mathrm{k}_{\mathrm{fAi}} \mathrm{P}_{\mathrm{Ap}}+\mathrm{k}_{\mathrm{fBi}} \mathrm{P}_{\mathrm{Bp}}\right)[\mathrm{i}]_{\mathrm{p}}
$$

Termination:

$\mathrm{k}_{\mathrm{t}}=\mathrm{k}_{\mathrm{tAA}} \mathrm{P}_{\mathrm{Ap}}^{2}+2 \mathrm{k}_{\mathrm{tAB}} \mathrm{P}_{\mathrm{Ap}} \mathrm{P}_{\mathrm{Bp}}+\mathrm{k}_{\mathrm{tBB}} \mathrm{P}_{\mathrm{Bp}}^{2}$

where $\mathrm{P}_{\mathrm{Ap}}$ and $\mathrm{P}_{\mathrm{Bp}}$ are the probabilities that the radicals contain monomeric units of type $\mathrm{A}$ or $\mathrm{B}$ at the active extremity. All other variables are described in the Appendix.

The model developed was implemented in FORTRAN and differential and algebraic equations were solved by the DASSL solver (Petzold, 1982). The model had been validated previously with experimental data on vinyl acetate emulsion homopolymerization reactions conducted at $55^{\circ} \mathrm{C}$ in the PSPC (Sayer et al., 2002a). All simulations were carried out using the method of lines with 50 internal points evenly distributed in the axial direction.

\section{RESULTS AND DISCUSSION}

In order to evaluate how the butyl acrylate comonomer affects the kinetics of vinyl acetate emulsion polymerization reactions, the results of a vinyl acetate/butyl acrylate copolymerization reaction were compared with those of vinyl acetate (VA) and butyl acrylate (BA) homopolymerization reactions (see formulations in Table 1). In the copolymerization $15 \mathrm{wt} . \%$ of monomer is composed of butyl acrylate. Tables 2 and 3 show the operational conditions and the kinetic constants and parameters used in the simulations.

Table 1: Formulation of VA/BA emulsion homo- and copolymerization reactions.

\begin{tabular}{|l|c|c|c|}
\hline \multirow{2}{*}{ Reactant } & VA & BA & VA/BA \\
\cline { 2 - 4 } & \multicolumn{3}{|c|}{ Mass fraction } \\
\hline VA & 0.1878 & - & 0.1596 \\
$\mathrm{BA}$ & - & 0.1878 & 0.0282 \\
Water & 0.8069 & 0.8069 & 0.8069 \\
$\mathrm{SLS}$ & 0.0024 & 0.0024 & 0.0024 \\
$\mathrm{Na}_{2} \mathrm{~S}_{2} \mathrm{O}_{8}$ & 0.0029 & 0.0029 & 0.0029 \\
\hline
\end{tabular}


Table 2: Operational conditions.

\begin{tabular}{|l|c|}
\hline Temperature $\left({ }^{\mathbf{0}} \mathbf{C}\right)$ & 55 \\
Residence time (min.) & 30 \\
Stroke length (mm) & 5 \\
Peclet number & 92 \\
\hline
\end{tabular}

Table 3: Parameters used in the simulations ( $\mathrm{A}$ - vinyl acetate/B - butyl acrylate).

\begin{tabular}{|c|c|c|}
\hline Parameter & Value & Reference \\
\hline $\mathrm{k}_{\mathrm{d}}(1 / \mathrm{s})$ & $1.8 .10^{17} \exp [-17155 / \mathrm{T}]$ & Rawlings and Ray, 1988 \\
\hline $\mathrm{k}_{\mathrm{pAA}}\left(\mathrm{cm}^{3} / \mathrm{mol} \mathrm{s}\right)$ & $1.445 .10^{10} \exp [-2490 / \mathrm{T}]$ & Hutchinson et al., 1995 \\
\hline $\mathrm{k}_{\mathrm{pBB}}\left(\mathrm{cm}^{3} / \mathrm{mol} \mathrm{s}\right)$ & $2.73 .10^{9} \exp [-3170 / \mathrm{T}]$ & McKenna et al., 1995 \\
\hline $\mathrm{k}_{\mathrm{pAB}}\left(\mathrm{cm}^{3} / \mathrm{mol} \mathrm{s}\right)$ & $\mathrm{k}_{\mathrm{pAA}} / \mathrm{r}_{\mathrm{A}}$ & \\
\hline $\mathrm{k}_{\mathrm{pBA}}\left(\mathrm{cm}^{3} / \mathrm{mol} \mathrm{s}\right)$ & $\mathrm{k}_{\mathrm{pBB}} / \mathrm{r}_{\mathrm{B}}$ & \\
\hline $\mathrm{k}_{\mathrm{fAA}}\left(\mathrm{cm}^{3} / \mathrm{mol} \mathrm{s}\right)$ & $2.43 .10^{-4} \mathrm{k}_{\mathrm{pAA}}$ & Chatterjee et al., 1977 \\
\hline $\mathrm{k}_{\mathrm{fBB}}\left(\mathrm{cm}^{3} / \mathrm{mol} \mathrm{s}\right)$ & $1.9 .10^{-4} \mathrm{k}_{\mathrm{pBB}}$ & Brandrup and Immergut, 1989 \\
\hline $\mathrm{k}_{\mathrm{fAB}}\left(\mathrm{cm}^{3} / \mathrm{mol} \mathrm{s}\right)$ & $\mathrm{k}_{\mathrm{fAA}} / \mathrm{r}_{\mathrm{A}}$ & \\
\hline $\mathrm{k}_{\mathrm{fBA}}\left(\mathrm{cm}^{3} / \mathrm{mol} \mathrm{s}\right)$ & $\mathrm{k}_{\mathrm{fBB}} / \mathrm{r}_{\mathrm{B}}$ & \\
\hline $\mathrm{k}_{\mathrm{tAA}}\left(\mathrm{cm}^{3} / \mathrm{mol} \mathrm{s}\right)$ & $5.255 .10^{9} \exp [-884 / \mathrm{T}]$ & Baad et al., 1982 \\
\hline $\mathrm{k}_{\mathrm{tBB}}\left(\mathrm{cm}^{3} / \mathrm{mol} \mathrm{s}\right)$ & $1.680 .10^{7} \exp [-1409 / \mathrm{T}]$ & McKenna et al., 1995 \\
\hline $\mathrm{k}_{\mathrm{tAB}}\left(\mathrm{cm}^{3} / \mathrm{mol} \mathrm{s}\right)$ & $\mathrm{k}_{\mathrm{tAA}}$ & \\
\hline $\mathrm{a}_{\mathrm{s}}\left(\mathrm{cm}^{2} / \mathrm{mol}\right)$ & $57.10^{-16} \mathrm{~N}_{\mathrm{A}}$ & Min and Ray, 1978 \\
\hline$r_{\mathrm{m}}(\mathrm{cm})$ & $2.5 .10^{-7}$ & Min and Ray, 1978 \\
\hline$[\mathrm{E}]_{\mathrm{CMC}}\left(\mathrm{mol} / \mathrm{cm}^{3}\right)$ & $2.43 .10^{-6}$ & Unzueta and Forcada, 1997 \\
\hline $\mathrm{D}_{\mathrm{WA}}\left(\mathrm{cm}^{2} / \mathrm{s}\right)$ & $1.1 .10^{-5}$ & Min and Ray, 1978 \\
\hline $\mathrm{D}_{\mathrm{WB}}\left(\mathrm{cm}^{2} / \mathrm{s}\right)$ & $1.0 .10^{-5}$ & Gardon, 1968 \\
\hline $\mathrm{D}_{\mathrm{pA}}\left(\mathrm{cm}^{2} / \mathrm{s}\right)$ & $1.1 .10^{-6}$ & Min and Ray, 1978 \\
\hline $\mathrm{D}_{\mathrm{pB}}\left(\mathrm{cm}^{2} / \mathrm{s}\right)$ & $1.0 .10^{-7}$ & Gardon, 1968 \\
\hline $\mathrm{f}_{\mathrm{absA}}$ & $3.3 .10^{-3}$ & - \\
\hline$f_{a b s B}$ & $1.0 .10^{-5}$ & - \\
\hline $\mathrm{f}_{\mathrm{absmA} A}$ & $1.0 .10^{-5}$ & - \\
\hline $\mathrm{f}_{\mathrm{absmB}}$ & $1.0 .10^{-7}$ & - \\
\hline $\mathrm{c}_{\mathrm{cA}}{ }^{0}(1 / \mathrm{s})$ & $4 \cdot 0.10^{-26}$ & - \\
\hline $\mathrm{c}_{\mathrm{cB}}^{0}(1 / \mathrm{s})$ & 0.0 & - \\
\hline $\mathrm{c}_{\mathrm{homA}}{ }^{0}(1 / \mathrm{s})$ & $3.0 .10^{-3}$ & - \\
\hline $\mathrm{c}_{\mathrm{homB}}{ }^{0}(1 / \mathrm{s})$ & $1.0 .10^{-5}$ & - \\
\hline $\mathrm{j}_{\text {critA }}$ & 16 & Gilbert, 1995 \\
\hline $\mathrm{j}_{\text {critB }}$ & 8 & Gilbert, 1995 \\
\hline $\mathrm{j}_{\mathrm{zA}}$ & 8 & Gilbert, 1995 \\
\hline $\mathrm{j}_{\mathrm{ZB}}$ & 1 & Gilbert, 1995 \\
\hline $\mathrm{PM}_{\mathrm{A}}(\mathrm{g} / \mathrm{mol})$ & 86.09 & Brandrup and Immergut, 1989 \\
\hline $\mathrm{PM}_{\mathrm{B}}(\mathrm{g} / \mathrm{mol})$ & 128.17 & Brandrup and Immergut, 1989 \\
\hline $\mathrm{PM}_{\mathrm{E}}(\mathrm{g} / \mathrm{mol})$ & 288.38 & Brandrup and Immergut, 1989 \\
\hline $\mathrm{PM}_{\mathrm{w}}(\mathrm{g} / \mathrm{mol})$ & 18.01 & Perry and Chilton, 1980 \\
\hline$\rho_{\mathrm{mA}}\left(\mathrm{g} / \mathrm{cm}^{3}\right)$ & 0.933 & Brandrup and Immergut, 1989 \\
\hline$\rho_{\mathrm{mB}}\left(\mathrm{g} / \mathrm{cm}^{3}\right)$ & 0.8 & Brandrup and Immergut, 1989 \\
\hline$\rho_{\mathrm{pA}}\left(\mathrm{g} / \mathrm{cm}^{3}\right)$ & 1.13 & Araújo et al., 2000 \\
\hline$\rho_{\mathrm{pB}}\left(\mathrm{g} / \mathrm{cm}^{3}\right)$ & 0.933 & Brandrup and Immergut, 1989 \\
\hline$\rho_{\mathrm{w}}\left(\mathrm{g} / \mathrm{cm}^{3}\right)$ & 1.028 & Perry and Chilton, 1980 \\
\hline $\mathrm{k}_{\mathrm{A}}^{\mathrm{d}}$ & 34.7 & Gardon, 1968 \\
\hline $\mathrm{k}_{\mathrm{B}}^{\mathrm{d}}$ & 705.0 & Unzueta and Forcada, 1997 \\
\hline $\mathrm{k}_{\mathrm{A}}^{\mathrm{p}}$ & 29.5 & Gardon, 1968 \\
\hline $\mathrm{k}_{\mathrm{B}}^{\mathrm{p}}$ & 460.0 & Unzueta and Forcada, 1997 \\
\hline $\mathrm{r}_{\mathrm{A}}$ & 0.037 & Gugliotta et al., 1995 \\
\hline $\mathrm{r}_{\mathrm{B}}$ & 6.35 & Gugliotta et al., 1995 \\
\hline
\end{tabular}




\section{A Comparison of VA/BA Homo- and Co- Polymerization Reactions}

Figure 2a compares the evolution of the overall conversions in the PSPC during emulsion VA/BA (85/15) copolymerization and VA and BA homopolymerization reactions. It can be observed that while in the VA and BA homopolymerizations conversions above $95 \%$ are reached at the reactor outlet, in the VA/BA (85/15) copolymerization the conversion at the reactor outlet is below $20 \%$. This occurs because the more reactive monomer in this copolymerization (BA) acts as a retardant of the propagation of the other monomer (VA). This can be verified in Figure $2 b$, which shows the evolution of the VA and BA fractional conversions in the PSPC during VA/BA (85/15) emulsion copolymerization reactions.

The significant reduction in the reaction rate of the copolymerization reaction compared to those of the copolymerizations may jeopardize this type of reactions in the PSPC, since very long residence times would be required in order to achieve complete monomer conversion. Therefore, in order to enhance the reaction rate, simulations presented below were carried out using a new reaction formulation with higher emulsifier and initiator concentrations, as shown in Table 4.

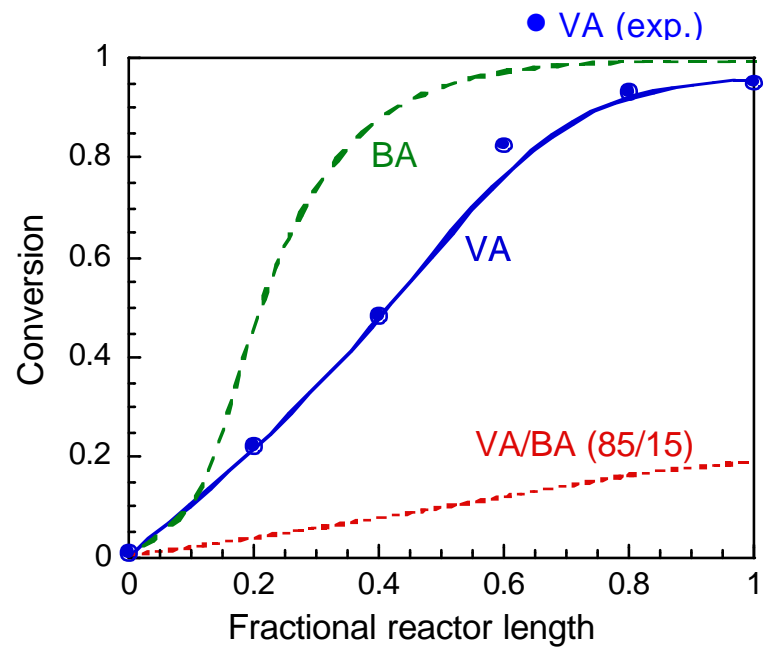

(a)

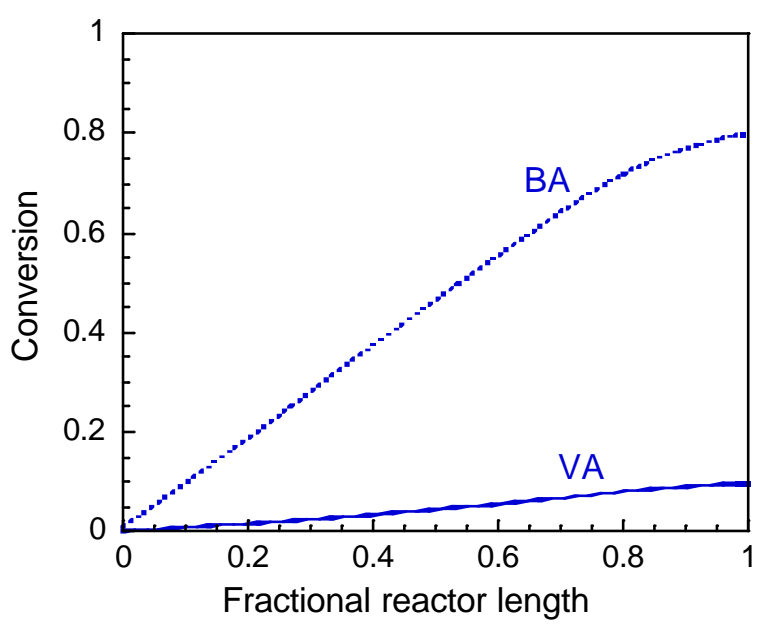

(b)

Figure 2: Conversions in the PSPC during VA and BA emulsion homo- and copolymerization reactions. (a) Overall conversions; (b) Fractional conversions.

Table 4: New formulation of VA/BA emulsion copolymerization reactions.

\begin{tabular}{|c|c|}
\hline Reactant & Mass fraction \\
\hline VA & 0.1576 \\
BA & 0.0279 \\
Water & 0.7969 \\
$\mathrm{SLS}$ & 0.0119 \\
$\mathrm{Na}_{2} \mathrm{~S}_{2} \mathrm{O}_{8}$ & 0.0057 \\
\hline
\end{tabular}

Figure 3a shows the evolution of overall and fractional conversions in the reactor of a reaction carried out in the PSPC using the new formulation. It might be observed that by increasing emulsifier and initiator concentrations, it is possible to reach high conversions in a relatively low residence time. On the other hand, copolymer composition (Figure 3b) shows a significant drift along the reactor length, resulting in the production of a quite heterogeneous copolymer.

\section{The effect of Axial Dispersion}

Figure 4a shows the effect of axial dispersion, which is varied through the Peclet number $(\mathrm{Pe})$, on the composition of the copolymer formed in the 
PSPC. It might be observed that a copolymer with a constant composition is only formed when the reactor is operated under conditions that are close to those of perfect mixing $(\mathrm{Pe}=0.14)$. Nevertheless, those conditions result in very low conversions, as shown in Figure $4 b$, which shows the effect of Pe on conversion in the PSPC.

\section{The effect of Lateral Feed Streams}

A way of minimizing the copolymer composition drift along the reactor length without significantly affecting the conversion is to use lateral feed streams of the more reactive monomer.

Figures $5 \mathrm{a}$ and $\mathrm{b}$ show the evolution of overall and fractional conversions and copolymer composition in the PSPC of a reaction performed with two lateral BA feed streams. It might be observed that with this procedure the copolymer composition shows a much less accentuated drift in the reactor, resulting in the production of a more homogeneous copolymer.

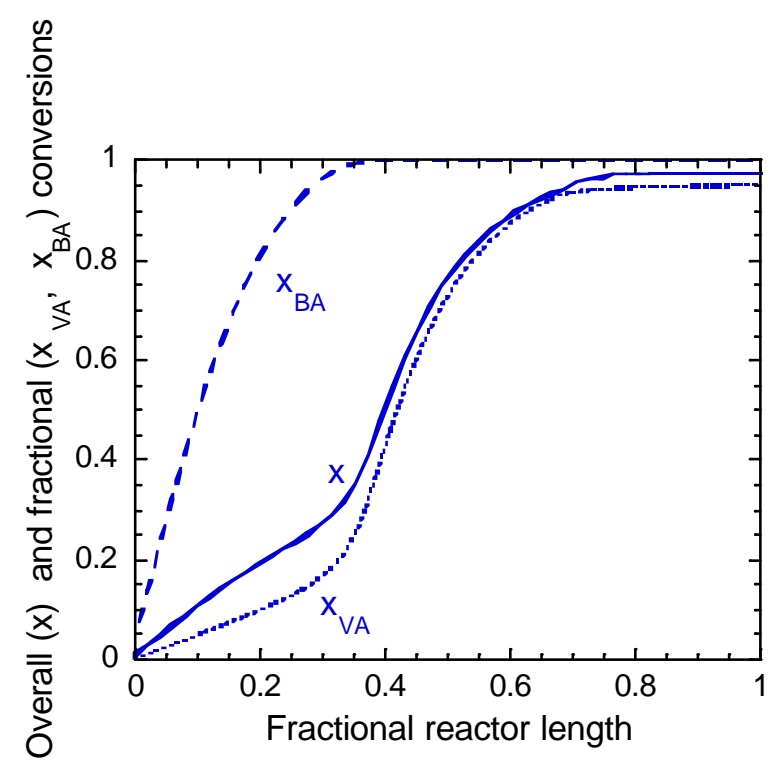

(a)

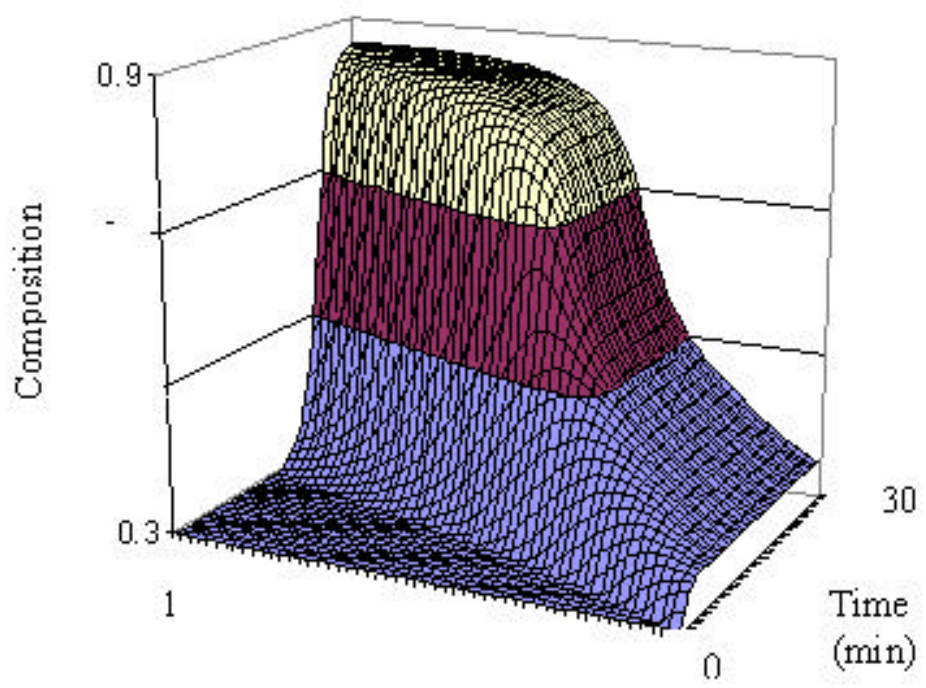

Fractional reactor length

(b)

Figure 3: Conversions and copolymer composition in the PSPC during VA and BA emulsion copolymerization reactions - new formulation (Table 4). (a) Overall and fractional conversions; (b) Copolymer composition (mass fraction of VA). 


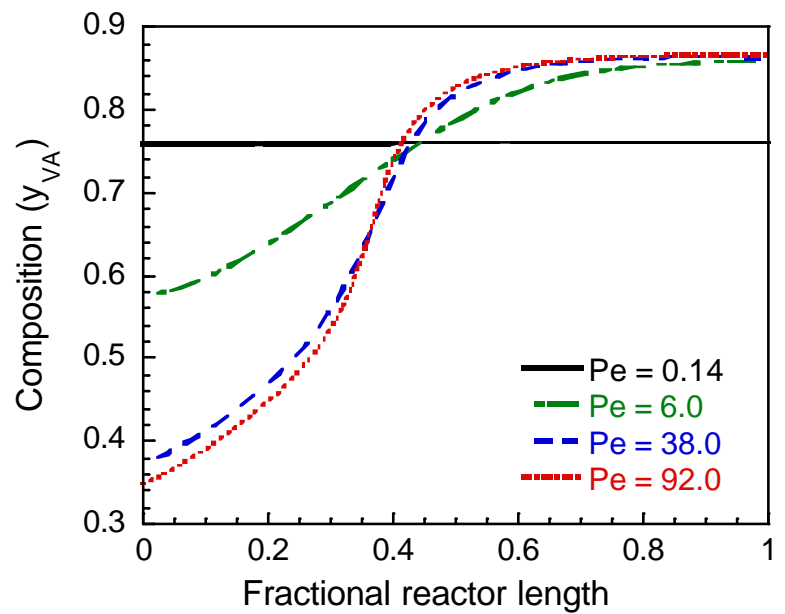

(a)

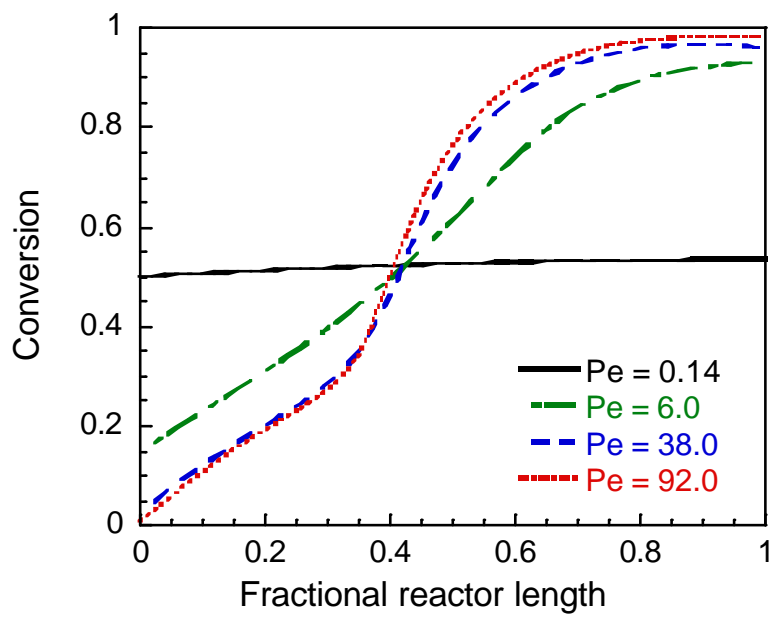

(b)

Figure 4: Effect of Peclet number on copolymer composition and overall conversion in the PSPC during VA and BA emulsion copolymerization reactions. (a) Copolymer composition (mass fraction of VA); (b) Overall and fractional conversions.

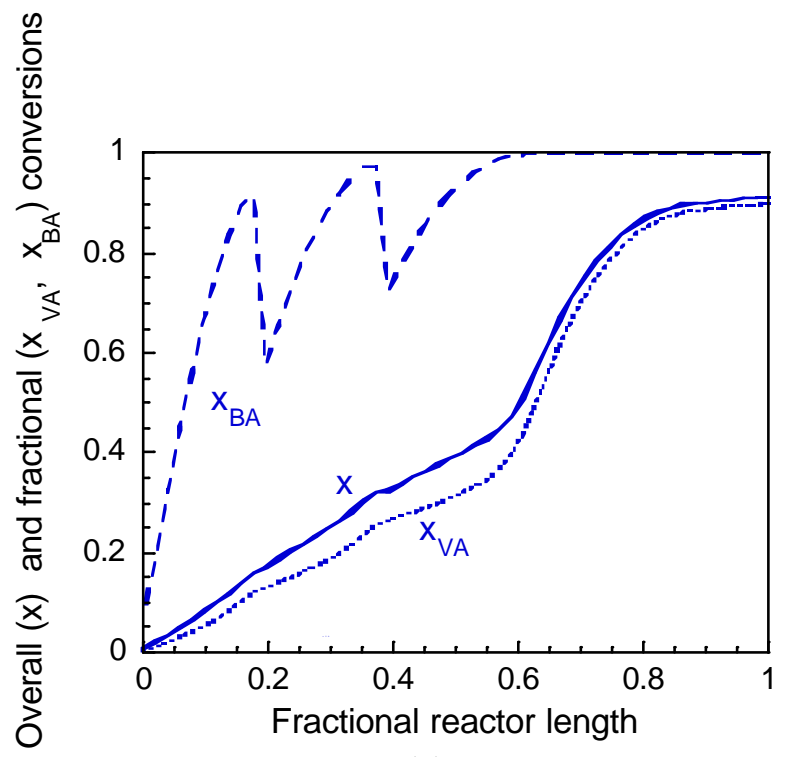

(a) 


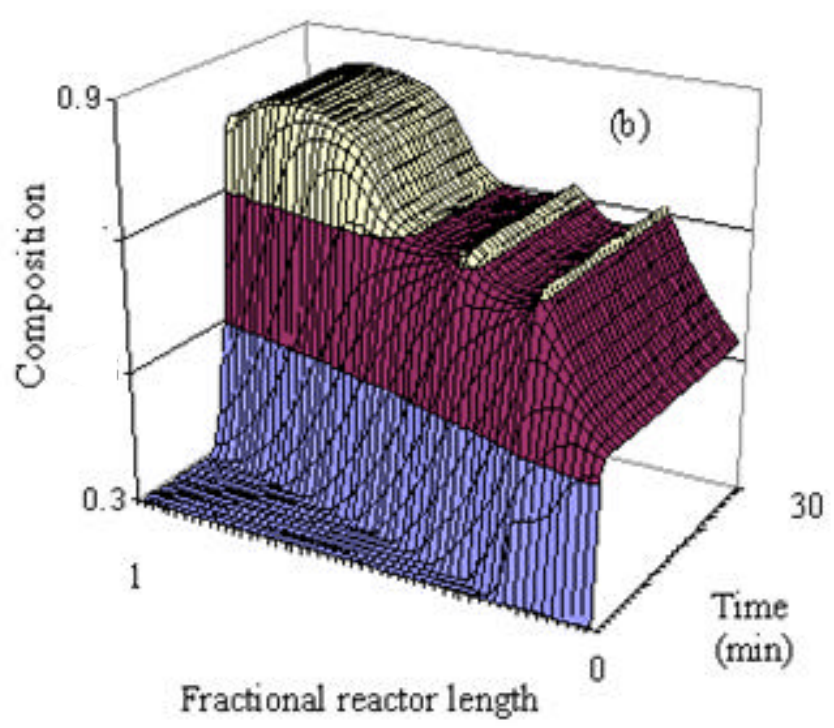

(b)

Figure 5: Conversions and copolymer composition in the PSPC during VA and BA emulsion copolymerization reactions with two lateral BA feed streams. (a) Overall and fractional conversions; (b) Copolymer composition (mass fraction of VA).

\section{CONCLUSIONS}

This work involved a computational study of vinyl acetate/butyl acrylate emulsion copolymerization reactions in the pulsed sieve-plate column reactor (PSPC). It was observed that due to the significant difference between the reactivity ratios of these two monomers, vinyl acetate/butyl acrylate emulsion copolymerization reactions are significantly slower than the vinyl acetate or butyl acrylate copolymerization reactions carried out under the same operational conditions. Therefore, a new formulation with higher initiator and emulsifier concentrations was tested. With this new formulation it was possible to achieve high conversions $(\sim 100 \%)$ in a relatively low residence time (30 minutes). Nevertheless, also due to the significant difference between the reactivity ratios of these two monomers, the copolymer composition showed a considerable drift along the reactor length, thereby resulting in a quite heterogeneous copolymer. It was verified that this composition drift can be minimized using lateral feed streams of the more reactive monomer in the copolymerization, in this case the butyl acrylate.

\section{ACKNOWLEDGEMENTS}

The financial support of FAPESP - Fundação de Amparao à Pesquisa do Estado de São Paulo - and
$\mathrm{CNPq}$ - Conselho Nacional de Desenvolvimento Científico e Tecnológico - are gratefully acknowledged.

\section{REFERENCES}

Araújo, O., Copolimerização e Terpolimerização em Emulsão: Trabalho Experimental e Estudo de Aspectos Relacionados à Modelagem Matemática do Processo, Ph.D. Diss., Universidade De São Paulo, Brazil, 1997.

Araújo, P.H.H., De La Cal, J.C., Asua, J.M. and Pinto, J.C., Modeling Particle Size Distribution (PSD) in Emulsion Copolymerization Reactions in a Continuous Loop Reactor, Computer-Aided Chem. Eng., vol. 8, Elsevier Science, pp. 565570, 2000.

Baad, W., Moritz, H.U. and Reichert, K.H., Kinetics of High Conversion Polymerization of Vinyl Acetate Effects of Mixing and Reactor Type on Polymer Properties, J. Appl. Polym. Sci., vol. 27, pp. 2249-2268, 1982.

Van Den Boomen, F.H.A.M., Meuldijk, J. and Thoenes, D., Emulsion Copolymerization in a Flexible Continuously Operated Reactor, Chem. Eng. Sci., vol. 54, pp. 3283-3290, 1999.

Brandrup, J. and Immergut, E.H., Polymer Handbook, 3rd ed., Wiley, New York, 1989.

Chatterjee, A., Park, W.S. and Graessley, W.W., 
Free Radical Polymerization with Long Chain Branching: Continuous Polymerization of Vinyl Acetate in tButanol, Chem. Eng. Sci., vol. 32, pp. 167-178, 1977.

Danckwerts, P.V., Continuous Flow Systems. Distribution of Residence Times, Chem. Eng. Sci., vol. 2, pp. 1-13, 1953.

Gardon, J.L., Emulsion Poly merization. II. Review of Experimental Data in the Context of the Revised Smith-Ewart Theory, J. Pol. Sci. A, vol. 6, pp. 643-664, 1968.

Gilbert, R.G., Emulsion Polymerization. $1^{\text {st }}$ ed. London, Academic Press, 1995.

Gugliotta, L.M., Arzamendi, G. and Asua, J.M., Choice of Monomer Partition Model in Mathematical Modeling of Emulsion Copolymerization Systems, J. Appl. Polym. Sci., vol. 55, pp. 1017-1039, 1995.

Hutchinson, R.A., Paquet, D.A., Mcminn, J.H., Beuermann, S., Fuller, R.E. and Jackson, C., Dechema Monogr. vol. 131, p. 467, 1995.

McKenna, T.F., Graillat, C. and Guillot, J., Contributions to Defining the Rate Constants for the Copolymerization of Butyl Acrylate and Vinyl Acetate, Pol. Bul. vol. 34, pp. 361-368, 1995.

Melis, S., Kemmere, M., Meuldijk, J., Storti, G. and Morbidelli, M., A Model for the Coagulation of the Polyvinyl Acetate Particles in Emulsion. Chem. Eng. Sci. vol. 55, pp. 3101-3111, 2000.

Min, K.W. and Ray, W.H., The Computer Simulation of Batch Emulsion Polymerization Reactors Through a Detailed Mathematical Model, J.Appl.Polym. Sci., vol. 22, pp. 89-112, 1978.

Omi, S., Kushibiki, K., Negishi, M. and Iso, M., Generalized Computer Modeling of SemiBatch, n-Component Emulsion Copolymerization Systems and Its Applications. Zairyo Gijutsu. vol.3, p. 426, 1985.

Palma, M., Sayer, C. and Giudici, R., Dechema Monogr., vol. 137, p. 625, 2001 a.
Palma, M., Miranda, S. C. F., Sayer, C. and Giudici, R., Comparação Entre Reações Contínuas de Polimerização em Emulsão em uma Coluna Pulsada com Pratos Perfurados com Reações em Batelada, $6^{\text {th }}$ CBPOL. Gramado, Brazil, 11-15th November, 2001b.

Perry, R.H. and Chilton, C.H., Manual de Engenharia Química, $5^{\text {th }}$ Ed., Guanabara Dois, Rio de Janeiro, 1980.

Petzold, L.R., A Description of Dassl: A Differential Algebraic System Solver, Sandia National Laboratories, Report \# SAND82-8637, 1982.

Rawlings, J.B. and Ray, W.R., The Modelling of Batch and Continuous Emulsion Polymerization Reactors: II. Comparison with Experimental Data from Continuous Stirred Tank Reactors, Polym. Eng. Sci., vol. 28, pp. 257-274, 1988.

Sayer, C., Palma, M. and Giudici, R., Modeling Continuous Vinyl Acetate Emulsion Polymerization Reactions in a Pulsed Sieve Plate Column, Ind. Eng. Chem. Res., vol. 41, pp. 17331744, 2002a.

Sayer, C., Palma, M. and Giudici, R., Kinetics of Vinyl Acetate Emulsion Polymerizations in a Pulsed Tubular Reactor. Comparison between Experimental and Simulation Results. Braz. J. Chem. Eng., vol. 19, pp. 425-431, 2002b ( $3^{\text {rd }}$ ENPROMER).

Scholtens, C.A., Meuldijk, J. and Drinkenburg, A.A.H., Production of Copolymers with a Predefined Intermolecular Chemical Composition Distribution by Emulsion Polymerization in a Continuously Operated Reactor, Chem. Eng. Sci., vol. 56, pp. 955-962, 2001.

Unzueta, E. and Forcada, J., Modeling the Effect of Mixed Emulsifier Systems in Emulsion Copolymerization, J. Appl. Polym. Sci., vol. 66, pp. 445-458, 1997.

Ugelstad, J., Moek, P.C. and Aasen, J.O., Kinetics of Emulsion Polymerization, J. Polym. Sci, vol. 5, pp. 2281-2287, 1967. 


\section{APPENDIX}

\section{EQUATIONS OF THE EMULSION POLYMERIZATION MODEL}

In order to model continuous reactions carried out in the PSPC, a dynamic axially dispersed plug-flow model was implemented. Given the assumptions shown in Section 3, the population and mass balance equations for a continuous emulsion polymerization system are presented below:

\section{a) Polymer Particle Concentration $-\mathbf{N}_{\mathbf{p}}$}

$$
\begin{aligned}
& \frac{\partial N_{p}}{\partial t}+v_{z} \frac{\partial N_{p}}{\partial z}-\operatorname{De} \frac{\partial^{2} N_{p}}{\partial z^{2}}= \\
& =R_{\text {mic }}+R_{\text {hom }}-c_{c}\left(N_{p}\right)^{2}
\end{aligned}
$$

where $v_{\mathrm{z}}$ is the axial velocity and De is the effective dispersion coefficient in $\mathrm{cm}^{2} / \mathrm{s}$ and

$$
\mathrm{v}_{\mathrm{z}}=\frac{\mathrm{q}_{\mathrm{e}}}{\left(\pi \mathrm{r}_{\text {col }}^{2} \mathrm{f}_{\text {void }}\right)}
$$

$\mathrm{De}=\mathrm{v}_{\mathrm{z}} \frac{\mathrm{a}_{\mathrm{col}}}{\mathrm{Pe}}$

where $\mathrm{q}_{\mathrm{e}}$ is the inlet flow rate of the reactor in $\mathrm{cm}^{3} / \mathrm{s}$; $\mathrm{r}_{\mathrm{col}}$ and $\mathrm{a}_{\mathrm{col}}$ are, respectively, the radius and the length of the PSPC in $\mathrm{cm}$ and $\mathrm{f}_{\text {void }}$ is the void fraction of the PSPC. Pe is the Peclet number, $R_{\text {mic }}$ and $R_{h o m}$ represent the micelar and homogeneous nucleation rates and $c_{c}\left(N_{p}\right)^{2}$ represents the rate of particle coalescence.

Micelar nucleation:

$\mathrm{R}_{\text {mic }}=\mathrm{k}^{\mathrm{m}}{ }_{\text {abs }} \mathrm{R}_{\text {ent }} \mathrm{N}_{\text {mic }}$

where $R_{\mathrm{ent}}$ is the concentration of radicals in the aqueous phase that may enter polymer particles and $\mathrm{k}^{\mathrm{m}}{ }_{\text {abs }}$ is the absorption rate coefficient of radicals from the aqueous phase by the micelles given by the Smoluchowski equation:

$\mathrm{k}^{\mathrm{m}}{ }_{\mathrm{abs}}=4 \pi \mathrm{D}_{\mathrm{w}} \mathrm{r}_{\mathrm{m}} \mathrm{Naf}^{\mathrm{m}}{ }_{\text {abs }}$ where $D_{w}, r_{m}$ and $f_{\text {abs }}^{m}$ represent, respectively, the diffusion coefficient in the aqueous phase, the radius of one micelle and the absorption efficiency of radicals from the aqueous phase by the micelles.

Variable $\mathrm{N}_{\text {mic }}$ is the concentration of micelles formed when the emulsifier concentration in the aqueous phase $[\mathrm{E}]^{\mathrm{aq}}$ is above the critical micelar concentration (CMC):

$\mathrm{N}_{\text {mic }}=\mathrm{M}_{\text {mic }} \mathrm{v}_{\mathrm{aq}}$

where $\mathrm{M}_{\text {mic }}$ is the number of micelles per volume of the aqueous phase and $\mathrm{v}_{\mathrm{R}}, \mathrm{v}_{\mathrm{p}}$ and $\mathrm{v}_{\mathrm{aq}}$ are, respectively, the volumes of the reactor and of the polymer and aqueous phases.

Homogeneous nucleation:

$\mathrm{R}_{\text {hom }}=\mathrm{c}_{\text {hom }}{ }^{0} \mathrm{k}_{\mathrm{p}}[\mathrm{M}]_{\mathrm{aq}} \mathrm{R}_{\text {jcrit }} \mathrm{Nav}_{\mathrm{aq}}$

where $c_{h o m}{ }^{0}$ is the coefficient of homogeneous nucleation and $k_{\mathrm{p}}[\mathrm{M}]_{\mathrm{aq}}$ is the propagation rate in the aqueous phase.

Variable $\mathrm{R}_{\text {jcrit }}$ is the concentration of radicals with the critical length $j_{\text {crit }}$ in the aqueous phase.

Particle coalescence:

In order to avoid using rather complex mathematical expressions like the extensions of the DLVO model (Derjaguin-Landau-VerweyOverbeek) that involve a significant number of often unknown parameters (Gilbert, 1995; Araújo et al., 2000), a simple equation for the rate constant of particle coalescence was used. This equation is an extremely simplified version of the DLVO model and the only effect that is accounted for in this equation is the initiator concentration in the aqueous phase, since increasing electrolyte concentrations enhances the particle coagulation rate (Melis et al., 2000):

$c_{c}=c_{c}^{0} \sqrt{[I] v_{R} N a}$

where $c_{c}^{0}$ is the only unknown parameter that must be adjusted in order to represent experimental data.

b) Initiator Concentration in the Reactor - [I]

$$
\frac{\partial[\mathrm{I}]}{\partial \mathrm{t}}+\mathrm{v}_{\mathrm{z}} \frac{\partial[\mathrm{I}]}{\partial \mathrm{z}}-\mathrm{De} \frac{\partial^{2}[\mathrm{I}]}{\partial \mathrm{z}^{2}}=-[\mathrm{I}] \mathrm{k}_{\mathrm{d}}
$$


c) Emulsifier Concentration in the Reactor - [E]

$\frac{\partial[E]}{\partial t}+v_{z} \frac{\partial[E]}{\partial z}-\operatorname{De} \frac{\partial^{2}[E]}{\partial z^{2}}=0$

In emulsion polymerization systems the emulsifier might be in three different forms: a) free in the aqueous phase $\left([E]^{\mathrm{aq}}\right)$; b) in the form of micelles in the aqueous phase $\left(\mathrm{M}_{\mathrm{mic}}\right)$; and $\left.\mathrm{c}\right)$ adsorbed on polymer particles $\left([\mathrm{E}]_{\mathrm{ads}}\right.$ ) and monomer droplets. As monomer droplets are significantly larger than polymer particles, they have a much smaller total surface area and, therefore, the amount of emulsifier adsorbed on monomer droplets might be neglected and

$[E]=\frac{[E]^{\mathrm{aq}} \mathrm{v}_{\mathrm{aq}}+\gamma \mathrm{M}_{\mathrm{mic}} \mathrm{v}_{\mathrm{aq}}+\mathrm{a}_{\mathrm{p}} \mathrm{N}_{\mathrm{p}}[\mathrm{E}]_{\mathrm{ads}}}{\mathrm{v}_{\mathrm{R}}}$

where $[E]^{\text {aq }}$ is the concentration of emulsifier in the aqueous phase, $\gamma$ is the number of moles of emulsifier per micelle and $[E]_{\mathrm{ads}}$ is the emulsifier adsorbed on polymer particles per unit surface. Variable $\gamma$ is computed by

$\gamma=\frac{4 \pi \mathrm{r}_{\mathrm{m}}^{2}}{\mathrm{a}_{\mathrm{s}}}$

where $a_{s}$ is the area covered by one mol of emulsifier and $a_{b}$ is the surface area of one polymer particle swollen with monomer:

$a_{p}=4 \pi r_{p}^{2}$

$r_{p}$ is the radius of one polymer particle swollen with monomer, computed by

$r_{p}=\sqrt[3]{\frac{3 v_{p} /\left(N_{p} v_{R}\right)}{4 \pi}}$

Variables $[\mathrm{E}]^{\mathrm{aq}}$, $[\mathrm{E}]_{\mathrm{ads}}$ and $\mathrm{M}_{\text {mic }}$ must be computed for three different situations: a) the emulsifier concentration is above the critical micelar concentration $\left([\mathrm{E}]_{\mathrm{CMC}}\right)$, so the emulsifier concentration in the aqueous phase $\left([\mathrm{E}]^{\mathrm{aq}}\right)$ equals $[\mathrm{E}]_{\mathrm{CMC}}$, the emulsifier concentration adsorbed on polymer particles $\left([\mathrm{E}]_{\mathrm{ad}}\right)$ equals the saturation concentration ( $[E]^{\mathrm{sat}}{ }_{\text {ads }}=1 / \mathrm{a}_{\mathrm{s}}$ ) and $\mathrm{M}_{\text {mic }}$ is computed with Eq. (A11); b) the emulsifier concentration is below $[\mathrm{E}]_{\mathrm{CMC}}$ and the emulsifier concentration is large enough to saturate polymer particles, so $\mathrm{M}_{\text {mic }}$ equals zero, $[\mathrm{E}]_{\mathrm{ad}}$ equals $[\mathrm{E}]^{\mathrm{sat}}{ }_{\text {ads }}$ (assuming that the emulsifier is absorbed on polymer particles than in the aqueous phase) and $[\mathrm{E}]^{\text {aq }}$ is computed with Eq. (A11); or c) the emulsifier concentration is below $[\mathrm{E}]_{\mathrm{CMC}}$ and the emulsifier concentration is not high enough to saturate polymer particles, so $\mathrm{M}_{\text {nic }}$ and $[E]^{\mathrm{aq}}$ equal zero and $[\mathrm{E}]_{\mathrm{ad}}$ is computed with Eq. (A11).

d) Monomer Concentration in the Reactor - $[\mathrm{M}]$

$$
\begin{aligned}
& \frac{\partial[\mathrm{M}]}{\partial \mathrm{t}}+\mathrm{v}_{\mathrm{z}} \frac{\partial[\mathrm{M}]}{\partial \mathrm{z}}-\mathrm{De} \frac{\partial^{2}[\mathrm{M}]}{\partial \mathrm{z}^{2}}= \\
& -\frac{\overline{\mathrm{nN}} \mathrm{N}_{\mathrm{p}}}{\mathrm{Na}}\left(\mathrm{k}_{\mathrm{p}}[\mathrm{M}]_{\mathrm{p}}+\mathrm{k}_{\mathrm{f}}[\mathrm{M}]_{\mathrm{p}}\right)
\end{aligned}
$$

$[\mathrm{M}]_{\mathrm{p}}$ is the monomer concentration in polymer particles. The monomer concentrations in the different phases in emulsion polymerization reactions were computed by the iterative procedure proposed by Omiet al. (1985).

\section{e) Polymer mass in the reactor $-\mathbf{P}$ :}

$$
\frac{\partial \mathrm{P}}{\partial \mathrm{t}}+\mathrm{v}_{\mathrm{z}} \frac{\partial \mathrm{P}}{\partial \mathrm{z}}-\mathrm{De} \frac{\partial^{2} \mathrm{P}}{\partial \mathrm{z}^{2}}=\frac{\overline{\mathrm{nN}} \mathrm{p}_{\mathrm{p}}}{\mathrm{Na}} \mathrm{k}_{\mathrm{p}}[\mathrm{M}]_{\mathrm{p}} \mathrm{PM}_{\mathrm{m}}
$$

\section{f) Water Fraction in the Reactor $-\phi_{\mathrm{w}}$ :}

$$
\frac{\partial \phi_{w}}{\partial \mathrm{t}}+\mathrm{v}_{\mathrm{z}} \frac{\partial \phi_{w}}{\partial \mathrm{z}}-\operatorname{De} \frac{\partial^{2} \phi_{w}}{\partial \mathrm{z}^{2}}=0
$$

\section{g) Computation of the Average Number of Radicals Per Polymer Particle}

The method proposed by Ugelstad et al. (1967) was used for the iterative computation of the average number of radicals per polymer particle $\bar{n}$ :

$$
\overline{\mathrm{n}}=\frac{1}{2} \frac{\mathrm{h}^{2} / 4}{\mathrm{~m}+0+\frac{\mathrm{h}^{2} / 4}{\mathrm{~m}+1+\frac{\mathrm{h}^{2} / 4}{\mathrm{~m}+2+\ldots}}}
$$

where $\mathrm{h}$ and $\mathrm{m}$ are the relative absorption/termination and desorption/termination coefficients, defined as 


$$
\begin{aligned}
& \mathrm{h}=\left(\frac{8 \mathrm{k}_{\mathrm{abs}} \mathrm{R}_{\mathrm{ent}} \mathrm{Nav}_{\mathrm{p}}}{\mathrm{k}_{\mathrm{t}} \operatorname{xgelN}_{\mathrm{p}} \mathrm{v}_{\mathrm{R}}}\right)^{\frac{1}{2}} \\
& \mathrm{~m}=\frac{\mathrm{kNav}_{\mathrm{p}}}{\mathrm{k}_{\mathrm{t}} \operatorname{xgelN}_{\mathrm{p}} \mathrm{v}_{\mathrm{R}}}
\end{aligned}
$$

$k_{a b s}$ is the coefficient of the rate of absorption of radicals from the aqueous phase by the polymer particles, given by the Smoluchowski equation:

$\mathrm{k}_{\mathrm{abs}}=4 \pi \mathrm{D}_{\mathrm{w}} \mathrm{r}_{\mathrm{p}} \mathrm{Naf}_{\mathrm{abs}}$

where $R_{\mathrm{ent}}$ is the concentration of radicals in the aqueous phase that may enter polymer particles. $R_{\text {ent }}$ is computed by the iterative procedure developed by Araújo et al. (2000) based on two different critical radical lengths proposed by Gilbert (1995):

$$
\begin{aligned}
& \Psi=\mathrm{k}_{\mathrm{p}}[\mathrm{M}]_{\mathrm{aq}}+\mathrm{k}_{\mathrm{abs}} \frac{\mathrm{N}_{\mathrm{p}} \mathrm{v}_{\mathrm{R}}}{\mathrm{v}_{\mathrm{aq}} \mathrm{Na}}+ \\
& +\mathrm{k}_{\mathrm{abs}}^{\mathrm{m}} \frac{\mathrm{N}_{\mathrm{mic}_{\mathrm{R}}} \mathrm{v}_{\mathrm{R}}}{\mathrm{v}_{\mathrm{aq}} \mathrm{Na}}+\mathrm{k}_{\mathrm{t}} \mathrm{R}_{\mathrm{aq}} \\
& \mathrm{R}_{1}=\left(\frac{\left.\frac{2 \mathrm{Iv}_{\mathrm{R}} \mathrm{fk}_{\mathrm{d}}}{\mathrm{v}_{\mathrm{aq}}}+\frac{\mathrm{k} \overline{\mathrm{n}} \mathrm{N}_{\mathrm{p}} \mathrm{v}_{\mathrm{R}}}{\mathrm{k}_{\mathrm{p}}[\mathrm{M}]_{\mathrm{aq}}+\mathrm{k}_{\mathrm{t}} \mathrm{R}_{\mathrm{aq}}}\right)}{\mathrm{R}_{\mathrm{jcrit}}=\mathrm{R}_{1}\left(\frac{\mathrm{k}_{\mathrm{p}}[\mathrm{M}]_{\mathrm{aq}}}{\mathrm{k}_{\mathrm{p}}[\mathrm{M}]_{\mathrm{aq}}+\mathrm{k}_{\mathrm{t}} \mathrm{R}_{\mathrm{aq}}}\right)}\right)^{\left(\mathrm{j}_{\mathrm{z}}-2\right)} \\
& \left(\frac{\mathrm{k}_{\mathrm{p}}[\mathrm{M}]_{\mathrm{aq}}}{\Psi}\right)^{\left(\mathrm{j}_{\mathrm{crit}}-\mathrm{j}_{\mathrm{z}}\right)}
\end{aligned}
$$

$$
\begin{aligned}
& \mathrm{R}_{\mathrm{ent}}=\mathrm{R}_{1}\left(\frac{\mathrm{k}_{\mathrm{p}}[\mathrm{M}]_{\mathrm{aq}}}{\mathrm{k}_{\mathrm{p}}[\mathrm{M}]_{\mathrm{aq}}+\mathrm{k}_{\mathrm{t}} \mathrm{R}_{\mathrm{aq}}}\right)^{\left(\mathrm{j}_{\mathrm{z}}-2\right)} \\
& \sum_{\mathrm{j}=\mathrm{j}_{\mathrm{z}}}^{\mathrm{jcrit}-1}\left(\frac{\mathrm{k}_{\mathrm{p}}[\mathrm{M}]_{\mathrm{aq}}}{\Psi}\right)^{(\mathrm{j}-\mathrm{j}+1)} \\
& \mathrm{R}_{\mathrm{aq}}=\mathrm{R}_{1}\left[1+\sum_{\mathrm{j}=2}^{\mathrm{j}_{\mathrm{z}}-1}\left(\frac{\mathrm{k}_{\mathrm{p}}[\mathrm{M}]_{\mathrm{aq}}}{\mathrm{k}_{\mathrm{p}}[\mathrm{M}]_{\mathrm{aq}}+\mathrm{k}_{\mathrm{t}} \mathrm{R}_{\mathrm{aq}}}\right)^{(\mathrm{j}-1)}\right]+\mathrm{R}_{\mathrm{ent}}
\end{aligned}
$$

where $R_{\mathrm{aq}}$ is the concentration of radicals in the aqueous phase; $j_{z}$ and $j_{\text {rit }}$ are the critical lengths for radical entry into micelles and polymer particles and for homogeneous nucleation (Gilbert, 1995), which depend on the solubility of the monomer in the aqueous phase; $\mathrm{k}_{\mathrm{t}} \mathrm{R}_{\mathrm{aq}}$ and $\mathrm{k}_{\mathrm{p}}[\mathrm{M}]_{\mathrm{aq}}$ are termination and propagation rates in the aqueous phase per unit radical; $f$ is the efficiency in forming radicals by decomposition of the initiator and $\mathrm{k}$ is the coefficient of the rate of desorption of radicals from polymer particles:

$$
\mathrm{k}=\mathrm{k}_{\mathrm{f}}[\mathrm{M}]_{\mathrm{p}} \frac{\mathrm{k}_{0 \mathrm{~m}}}{\left(\mathrm{k}_{0 \mathrm{~m}} \beta_{\mathrm{m}}+\mathrm{k}_{\mathrm{p}}[\mathrm{M}]_{\mathrm{p}}\right)}
$$

where $\mathrm{k}_{\mathrm{m}}$ and $\beta_{\mathrm{m}}$ are the exit rate of a monomeric radical from a polymer particle and the probability that a radical in the aqueous phase will react by propagation or by termination:

$$
\begin{gathered}
\mathrm{k}_{0 \mathrm{~m}}=\frac{3 \frac{\mathrm{D}_{\mathrm{w}}}{\mathrm{r}_{\mathrm{p}} \mathrm{k}_{\mathrm{m}}^{\mathrm{p}}}}{2 \frac{\mathrm{D}_{\mathrm{w}}}{\mathrm{D}_{\mathrm{p}} \mathrm{k}_{\mathrm{m}}^{\mathrm{p}}}+1} \\
\beta_{\mathrm{m}}=\frac{\left(\mathrm{k}_{\mathrm{p}}[\mathrm{M}]_{\mathrm{w}}+\mathrm{k}_{\mathrm{t}} \mathrm{R}_{\mathrm{aq}}\right)}{(\psi)}
\end{gathered}
$$

where $D_{p}$ is the diffusion coefficient of a radical in polymer particles in $\mathrm{cm}^{2} / \mathrm{s}$. 